\title{
AVALIAÇÃO DA EFICIÊNCIA DE EXTRAÇÃO DOS POLIFENÓIS DE AMOSTRAS DE CHÁ ATRAVÉS DE MÉTODOS DOMÉSTICOS
}

Maria Fernanda de Moura Leão, Jonathaline Apollo Duarte, Elizandra Gomes Schmitt, Luciane Dias Quintana, Léa Augusta de Bairros Zambrano, Mariana Balhego Rocha,

Luísa Zuravski, Luís Flávio Souza de Oliveira e Michel Mansur Machado*

Submetido em: 26/06/2015

Aceito em: 12/04/2016

Universidade Federal do Pampa, Rio Grande do Sul, Brasil

E-mail*: michelmachado@unipampa.edu.br

\section{Resumo}

Os polifenóis são metabólitos secundários de origem vegetal, os quais possuem reconhecida atividade antioxidante, que está centrada na neutralização de radicais livres. Esses compostos estão comumente presentes na alimentação de humanos, como no chá, que é uma das bebidas mais antigas e mais consumidas ao redor do mundo. O objetivo deste trabalho foi verificar, sob condições caseiras, a melhor forma de se extrair a maior quantidade de polifenóis, a partir dos chás branco e verde. As amostras para os testes foram obtidas a partir de três marcas comerciais de chás. Para o desenvolvimento dos testes, as amostras foram separadas em oito grupos, sendo cada grupo constituído de seis amostras em diferentes condições de preparo. Os resultados mostraram que sob condições caseiras, a melhor forma para a extração de polifenóis é por meio da água quente, a uma temperatura de pré-fervura $\left(80^{\circ} \mathrm{C}\right)$ durante um tempo prolongado.

Palavras-chave: Chá, Antioxidante, Polifenóis.

\section{Evaluation of the efficiency of extraction of polyphenols from tea samples through domestic methods}

\section{Abstract}

Polyphenols are secondary metabolites of plant origin, which have recognized antioxidant activity, which is centered in neutralizing free radicals. These compounds are commonly present in human food, such as tea, which is one of the oldest and most widely consumed beverages around the world. The objective of this study was to verify, under home conditions, the best way to extract the highest amount of polyphenols from green and white teas. The samples for testing were obtained from three commercial brands of teas. In order to develop the tests, the samples were divided into eight groups, each group consisting of six samples prepared under different conditions. The results showed that in home conditions, the best extraction of polyphenols is hot water at a pre-boil temperature $\left(80^{\circ} \mathrm{C}\right)$ for a prolonged time.

Keywords: Tea, Antioxidant, Polyphenols.

\section{Evaluación de la eficiencia de extracción de polifenoles de las muestras del té através de métodos domésticos}

\section{Resumen}

Los polifenoles son metabolitos secundarios de origen vegetal, que tienen reconocida actividad antioxidante concentrada en la neutralización de los radicales libres. Esos compuestos están comúnmente presentes en la alimentación humana, tales como 
el té, que es una de las bebidas más antiguas y más ampliamente consumidas en el mundo. El objetivo de este estudio fue verificar, en condiciones caseras, la mejor manera de extraer la mayor cantidad de polifenoles, a partir de los tés blanco y verde. Las muestras para las pruebas se obtuvieron de tres marcas comerciales de tés. Para el desarrollo de las pruebas, las muestras se dividieron en ocho grupos, cada grupo consta de seis muestras preparadas en condiciones diferentes. Los resultados mostraron que en condiciones caseras, la mejor manera de extracción de polifenoles es por intermedio de agua caliente, a una temperatura de pre-hervor de ebullición $\left(80^{\circ} \mathrm{C}\right)$ durante un tiempo prolongado.

Palabras-clave: Polifenoles, Té, Antioxidante.

\section{INTRODUÇÃO}

Desde tempos antigos, os seres humanos têm buscado benefícios de produtos derivados de produtos naturais e seus compostos. É reconhecido que a tradicional medicina chinesa possui técnicas únicas para prevenção e tratamento de doenças relacionadas a presença de radicais livres. Adicionalmente, existem evidências consideráveis do uso de polifenóis como potenciais agentes terapêuticos ${ }^{(1)}$.

Os polifenóis são metabólitos secundários de origem vegetal, representados, principalmente, por flavonóides, cumarinas, lignanas e taninos, os quais possuem reconhecida atividade antioxidante, que está centrada na neutralização de radicais livres pelo deslocamento de elétrons do anel aromático, formando radicais mais estáveis, o que contribui para a diminuição do estresse oxidativo $0^{(1,2,3)}$.

Esses compostos estão comumente presentes na alimentação de humanos, como no chá, que é uma das bebidas mais antigas e mais consumidas ao redor do mundo, tanto pelo apelo cultural quanto terapêutico, pois está presente nas indicações da medicina tradicional, que são fundamentadas na presença de vários compostos ativos, como polifenóis, flavonóides, alguns minerais, entre outros componentes, despertando interesse na comunidade científica para estudar sua aplicação no tratamento de diversas doenças ${ }^{(3,4)}$.

Dentre as plantas mais utilizadas na preparação de chás está a Camellia sinensis (Theaceae), que é originária do sudeste da Ásia e também cultivada em mais de 30 países, devido a sua fácil adaptação. A partir do processamento da $C$. sinensis para ser consumida na forma de chá, pode-se obter três variações para o consumo, de acordo com o processo de produção adotado: O chá preto, produzido a partir da fermentação das folhas frescas de C. sinensis; o chá verde, produto não fermentado; e o chá branco, elaborado a partir dos brotos da planta(4,5).

Devido aos diferentes métodos de processamento para se obter os diferentes chás, as folhas de $C$. sinesis podem apresentar diferentes constituintes. As folhas de chá verde possuem grande quantidade de catequinas, principalmente epicatequinas, que são responsáveis pela coloração e pelo sabor amargo e adstringente desse tipo de chá. As folhas de chá preto, após o processo de laminação e secagem têm suas catequinas transformadas em teaflavinas responsáveis pela coloração alaranjada e pelo sabor do chá( $3,6,7)$. As estruturas das principais catequinas e das teaflavinas estão representadas na Figura 1. 
Figura 1: Estrutura principal das catequinas e das teaflavinas.<smiles>[R9]c1cc(C2Oc3cc(O)cc(O)c3CC2([R20])[R])cc(O)c1O</smiles>

\begin{tabular}{lccc} 
& $\mathrm{R}_{1}$ & $\mathrm{R}_{2}$ & $\mathrm{R}_{2}$ \\
\hline (+)-Catequina & $\mathrm{OH}$ & $\mathrm{H}$ & $\mathrm{H}$ \\
(-)-Epigalocatequina & $\mathrm{H}$ & $\mathrm{OH}$ & $\mathrm{OH}$ \\
() Epigalocatequina galato & $\mathrm{H}$ & galato & $\mathrm{OH}$ \\
(-)-Epicatequina & $\mathrm{H}$ & $\mathrm{OH}$ & $\mathrm{H}$ \\
(-)-Epicatequina galato & $\mathrm{H}$ & galato & $\mathrm{H}$ \\
\hline
\end{tabular}

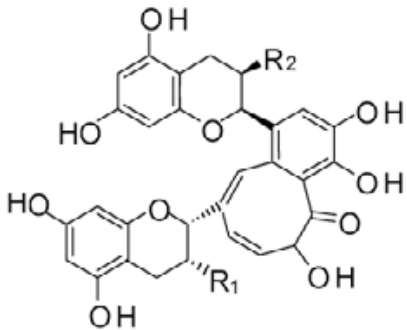

\begin{tabular}{lcc} 
& $\mathrm{R}_{1}$ & $\mathrm{R}_{2}$ \\
\hline Teaflavina 3-galato & galato & $\mathrm{OH}$ \\
Teaflavina & $\mathrm{OH}$ & $\mathrm{OH}$ \\
Teaflavina 3' -galato & $\mathrm{OH}$ & galato \\
Teaflavina 3-3'-digalato & galato & galato \\
\hline
\end{tabular}

O objetivo deste trabalho foi verificar, sob condições caseiras, a melhor forma de se extrair a maior quantidade de polifenóis, a partir dos chás branco e verde. Afinal, sabe-se que a temperatura pode influenciar na quantidade de polifenóis presentes nas amostras, fato observado já na preparação das folhas.

\section{MATERIAIS E MÉTODOS}

As amostras para os testes foram obtidas a partir de três marcas comerciais de chás. A quantidade de amostra preparada foi de dois sacos de chá para cada $250 \mathrm{~mL}$ de água mineral. O uso da água mineral gera uma menor influência de contaminantes da rede de abastecimento, como resíduos orgânicos ou de metais pesados.

Para o desenvolvimento dos testes, as amostras foram separadas em oito grupos, sendo cada grupo constituído de seis amostras, onde três delas eram de chá branco e as outras três de chá verde: Grupo 1 (Tto 01) - chá e água colocados em microondas com 900W de potência, por 2 minutos, condições estas que levavam o preparado até a fervura; Grupo 2 (Tto 02) - água e chá submetidos juntos ao aquecimento até $80^{\circ} \mathrm{C}$ (início da fervura e borbulhamento da água) em fogão a gás; Grupo 3 (Tto 03) - água aquecida até $80^{\circ} \mathrm{C}$ e depois colocado o chá por 3 minutos; Grupo 4 (Tto 04 ) - água aquecida até $80^{\circ} \mathrm{C}$ e depois colocado o chá por 10 minutos; Grupo 5 (Tto 05) - água aquecida até $80^{\circ} \mathrm{C}$ e depois colocado o chá por 15 minutos; Grupo 6 (Tto 06) - água aquecida até $80^{\circ} \mathrm{C}$ e depois colocado o chá por 30 minutos; Grupo 7 (Tto 07 ) - água aquecida até $80^{\circ} \mathrm{C}$ e depois colocado o chá por 60 minutos; grupo 8 (Tto 08) - água fria e chá por 3 minutos. Nos casos dos tratamentos com água aquecida até $80^{\circ} \mathrm{C}$, após atingir a temperatura indicada, as amostras foram deixadas na bancada a temperatura ambiente, ampliando o tempo de contato entre o solvente e o chá.

Determinação de polifenóis totais: Para o doseamento dos polifenóis foi utilizado o método de Chandra e Mejia(8), modificado, o qual usa Folin-Ciocalteau (reagente para fenóis) que permite a determinação indireta dos compostos fenólicos utilizando o ácido gálico como padrão para todos os fenóis. Nesta reação forma-se um complexo de cor azulada, que absorve radiação no comprimento de onda de $760 \mathrm{~nm}$. O método não é específico, porque outros compostos podem ser reduzidos, como açúcares e ácido ascórbico. As concentrações de polifenóis das amostras foram determinadas por comparação com a curva de calibração elaborada com o ácido pirogálico. Para o ensaio foram preparadas soluções de 0,15 mg/mL de cada amostra, onde 
se utilizou $10 \mathrm{~mL}$ etanol, de modo a solubilizar as frações. E, após o volume total, foi completado a $100 \mathrm{~mL}$ com água destilada. Ao volume de $1 \mathrm{~mL}$ das amostras foi adicionado $0,5 \mathrm{~mL}$ do reagente de Folin-Ciocalteau. Após 5 minutos, acrescentou-se $2 \mathrm{~mL}$ de carbonato de sódio $20 \%$ e as leituras das absorbâncias foram realizadas após 10 minutos, em $730 \mathrm{~nm}$. Todas as amostras foram preparadas em triplicata. A curva de calibração foi feita com ácido pirogálico nas concentrações de 0,$005 ; 0,01 ; 0,015$; 0,025 e $0,03 \mathrm{mg} / \mathrm{mL}$, e suas leituras procedidas da mesma forma das amostras. Para calibrar o espectrofotômetro (Shimadzu, UV-1021) foi utilizada água destilada.

\section{ANÁLISE ESTATÍSTICA}

Os dados foram analisados utilizando GraphPad Prism 5.0. As análises foram realizadas em triplicata e as variáveis analisadas pela análise de variância (ANOVA) One-way seguido de teste post hoc de Tukey. Os resultados foram expressos por média e desvio padrão, e considerados significativos quando $p<0.05$.

\section{RESULTADOS E DISCUSSÃO}

Na Figura 2 são mostradas as concentrações de ácido gálico nas duas preparações de chás branco (2A) e verde (2B) utilizadas. Como pode ser observado, no caso do chá branco, os processos que submeteram as preparações ao aquecimento demonstraram ser muito mais eficazes em extrair ácido gálico (flavonoides) que a extração a frio. E, dentre as extrações com energia térmica, o processo que utilizou micro-ondas foi mais efetivo que os restantes até o tempo de 15 minutos. Posteriormente a este período, ou seja, 30 e 60 minutos, houve uma efetividade maior na extração de ácido gálico pelos grupos 6 e 7, respectivamente, superando o processo com micro-ondas.

Em relação ao chá verde, o perfil de extração encontrado foi muito semelhante ao que aconteceu com o chá branco, com exceção do grupo 2, que conseguiu obter concentrações maiores de ácido gálico que o micro-ondas e equivalentes ao grupo 6. Destaca-se também que o grupo 8, que não utilizou energia térmica para extração, mas somente solvente em função de tempo (3 min.), também conseguiu extrair uma quantidade maior de ácido gálico, quando comparado ao grupo 8 de chá branco.

Figura 2: Concentração de polifenóis nas amostras de chás testados. Em " $A$ " chá Branco, em " $B$ ", chá Verde. Tto 01 - preparado (de chá e água) submetido ao micro-ondas até a fervura da água, Tto 02 - preparado aquecido até $80^{\circ} \mathrm{C}$ em fogão, Tto 03 - água aquecida até $80^{\circ} \mathrm{C}$ e depois colocado o chá por 3 minutos, Tto 04 - água aquecida até $80^{\circ} \mathrm{C}$ e depois colocado o chá por 10 minutos, Tto 05 - água aquecida até $80^{\circ} \mathrm{C}$ e depois colocado o chá por 15 minutos, Tto 06 - água aquecida até $80^{\circ} \mathrm{C}$ e depois colocado o chá por 30 minutos, Tto 07 - água aquecida até $80^{\circ} \mathrm{C}$ e depois colocado o chá por 60 minutos e Tto 08 - água fria e chá por 3 minutos. Os resultados são apresentados na forma de Média \pm Desvio Padrão. Letras diferentes sobrepostas às colunas significam resultados estatisticamente diferentes para um $p<0.05$. 

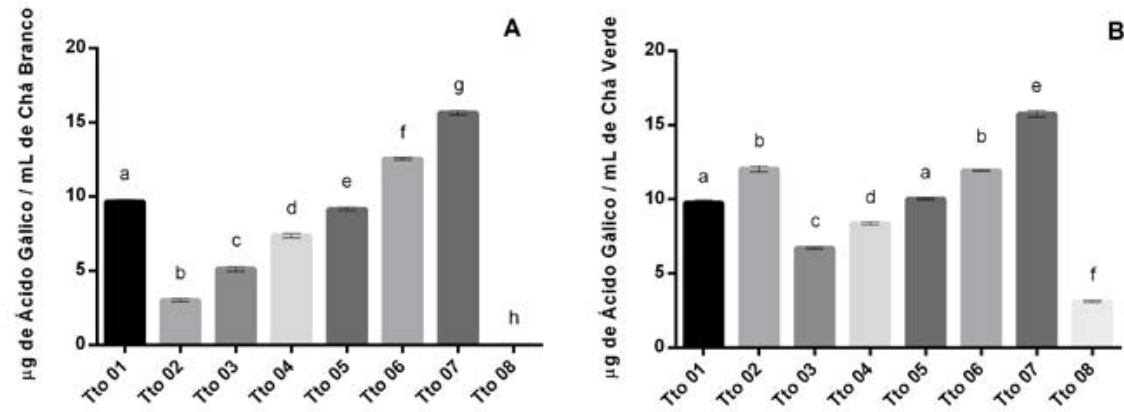

Dentre os 8 grupos, os melhores resultados foram obtidos com a água aquecida até $80^{\circ} \mathrm{C}$ por 60 minutos, obtendo uma média de 15,64 0,14 $\mu \mathrm{g} / \mathrm{mL}$ nas amostras de chá branco e 15,75 $\pm 0,20 \mu \mathrm{g} / \mathrm{mL}$ nas amostras de chá verde.

Para a extração de polifenóis, uma variedade de solventes é utilizada, desde misturas de solventes polares a apolares. Entretanto, como este estudo foi voltado para análise da efetividade de extração de métodos caseiros, o solvente usado foi a água, pois sabe-se que a água, devido à sua polaridade, extrai com eficiência compostos antioxidantes ${ }^{(9,10)}$. Durante o processo de extração, várias condições influenciam a quantidade de compostos extraídos, desde o processo de produção e o tipo de solo, o tipo de solvente utilizado no processo, a temperatrura aplicada e o tempo de extração ${ }^{(5,9)}$.

O efeito das condições de extração de polifenóis tem sido uma questão controversa, especialmente quando se compara diferentes matérias-primas. Muitos fatores, tais como a composição do solvente, o tempo de extração, a temperatura de extração e a proporção solvente sólido, pode influenciar significativamente a eficácia de extração e o rendimento. Em contraste, a extração assistida por micro-ondas é um processo rápido de extração onde a energia é eficientemente entregues aos materiais através da interação molecular com o campo eletromagnético, favorecendo o processo (11, 12).

O uso de micro-ondas para a extração de polifenóis tem se mostrado eficaz, quando comparada a outros métodos como, por exemplo, extração à temperatura ambiente, extração por ultrassom e extração por refluxo quente ${ }^{(13)}$. Estima-se que o tempo ideal para a extração satisfatória de polifenóis seja de quatro minutos, pois, a partir desse tempo, a quantidade de polifenóis extraída começa a diminuir. Neste sentido, nossos resultados corroboram com estudos anteriores, demonstrando que o processamento por micro-ondas é eficaz para a extração de compostos bioativos presentes em preparações sob a forma de chá por lesionar a parede celular devido a energia do micro-ondas ${ }^{(13)}$.

Dentro do contexto das concentrações de compostos bioativos presentes nos chás branco e verde, vale ressaltar que a característica geoquímica do solo é um fator importante para o crescimento da Camellia sinensis e para a composição dos seus metabólitos. Sabe-se que o acúmulo de metais no solo, principalmente de alumínio, gera um aumento no número de metabólitos antioxidantes produzidos pela planta. Este aspecto deve ser levado em consideração no momento de se relacionar a quantidade de compostos bioativos extraídos de chás e o seu país de origem(5,9).

Estudos anteriores relatam que o tempo de infusão e a quantidade de solvente utilizados são fatores determinantes para a extração de polifenóis, levando a uma maior extração de bioativos dos chás que permanecem mais tempo em infusão e com quantidade maior de solvente extrator. Esses achados se devem ao fato de haver condições mais favoráveis para um esgotamento vegetal adequado. Nossos resultados corroboram com os achados na literatura no que se refere ao fator tempo, pois após a realização dos testes foi verificado que a maior extração ocorreu no maior tempo(14). 
Durante o processo de extração, a temperatura pode influenciar a estabilidade dos polifenóis, podendo levar a reações enzimáticas, degradações e volatilização de compostos. Alguns estudos demonstram que a temperatura ideal para a extração de polifenóis é a de $80^{\circ} \mathrm{C}$, pois nessa temperatura há uma grande quantidade de polifenóis extraídos, mantendo-se, contudo, sua atividade biológica. Temperaturas mais elevadas podem levar à degradação dos compostos, diminuindo a quantidade de polifenóis no chá; para temperaturas superiores a $80^{\circ} \mathrm{C}$ o indicado é uma extração por menor tempo, entre 5-10 minutos $\left.{ }^{(9,}, 15\right)$. No presente estudo, isto explica, pelo menos em parte, o maior teor de ácido gálico encontrado nos grupos 6 e 7 (com maior tempo de contato e controle de temperatura) em relação ao grupo 1 (fervura em micro-ondas).

\section{CONCLUSÃO}

Em condições caseiras, a melhor forma de extração de polifenóis provindos de diferentes variedades de chá é a água quente, a uma temperatura de pré-fervura $\left(80^{\circ} \mathrm{C}\right)$ durante um tempo prolongado. Estes fatores são condicionantes para a extração de quantidades significativas de polifenóis, concorrendo para a preservação dos benefícios medicinais do chá.

\section{REFERÊNCIAS}

1. Cho EJ, Yokozawa T, Rhyu DY, Kim SC, Shibahara N, Park JC. Study on the inibitory effects of Korean medicinal plants and their main compounds on the 1, 1-dyphenyl-2-pierylhydrazyl radical. Phytomedicine. 2003; 10(6): 544-551.

2. Katz DL, Doughty K, Ali A. Cocoa and chocolate in human health and disease. Antioxidants\& Redox Signaling. 2011; 15(10): 2779-2811.

3. Scalbert A, Johnson IT, Saltmarsh M. Polyphenols: antioxidants and beyond. Am J Clin Nutr. 2005; 81: 215S-217S.

4. Mukhtar H, Ahmad N. Tea polyphenols: preventions of cancer and optimizin healt. Am J Clin Nutr. 2000; 71: 1698S- $1702 \mathrm{~S}$.

5. Lima JD, Mazzafera P, Moraes WS, Silva RB. Chá: aspectos relacionados à qualidade e perspectivas. Ciência Rural. 2009; 39(4): 1270-1278.

6. Matsubara S, Amaya DBR. Teores de catequinas e teaflavinas em chás comercializados no Brasil. Ciênc. Tecnol. Aliment. 2006; 26(2): 401-407.

7. Hilal Y, Engelhardt U. Characterisation of White tea - Comparasion to Green and Black tea. J of Consumer Protection and Food Safety. 2007; 2: 414-421.

8. Chandra S, Mejia EG. J Agric. Food Chem. 2004; 52: 3583.

9. Andreo D, Jorge N. Antioxidantes naturais: técnicas de extração. B. CEPPA. 2006; 24(2): 319-336.

10. Lapornik B, Prošek M, Wondra AG. Comparison of extracts prepared from plant by-products using differents solvents and extraction time. J Food and Engineering. 2005; 71: 214-222.

11. Yang, Li, et al. "Optimum extraction process of polyphenols from the bark of Phyllanthus emblica L. based on the response surface methodology." Journal of separation science 32.9 (2009): 1437-1444.

12. Yue, Tianli, et al. "Ultrasound-assisted extraction, HPLC analysis, and antioxidant activity of polyphenols from unripe apple." Journal of separation science 35.16 (2012): 2138-2145. 
13. Pan X, Niu G, Liu H. Microwave-assisted extraction of tea polyphenols and tea caffeine from Green tea leaves. Chem. Engineering and Processing. 2003; 42: 129-133.

14. Astill C, Birch MR, Dacombe C, Humphrey PG, Martin PT. Factors affecting the caffeine and polyphenols contents of Black and Green teas infusions. 2001; 49(11): 5340-5347.

15. Uzunalić AP, Škerget M, Željko K, Weinreich B, Otto F, Grüner S. Extraction of active ingredients from green tea (Camellia sinensis): Extraction efficiency of major catechins and caffeine. Food Chemistry. 2006; 96: 597-605. 